\title{
The management of acute hepatic failure
}

\section{Sheila Sherlock S. P. Parbhoo}

Departments of Medicine and Surgery, Royal Free Hospital, London W.C.1

\begin{abstract}
Summary
Acute fulminant hepatitis leads to complex biochemical and circulatory disturbances including coma. These can be predicted to some extent by knowledge of the functions of the normal liver cells. Ineffective haemostasis, coma, hypoglycaemia, electrolyte abnormalities, hypotension and renal circulatory failure are particularly important.

Management should be governed by the abnormalities found in the individual patient. Fluid overload and sedation must be avoided. More complex methods of temporary hepatic support such as exchange transfusion or perfusion of the isolated pig's liver should only be considered after simpler methods of correction have been attempted for a reasonable period of time and found wanting.

The prognosis of acute hepatocellular failure reaching the stage of deep coma is very poor, the mortality being about $80-90 \%$.
\end{abstract}

ACUTE hepatocellular failure must be distinguished from chronic failure for the more elaborate procedures of temporary hepatic support such as exchange blood transfusion or the isolated perfused liver are not justifiable in the presence of chronic irreversible liver disease. A careful search must therefore be made for evidence of underlying chronic liver disease such as a prolonged history, a large hard liver, gross ascites, marked splenomegaly and vascular spiders on the skin. The most frequent cause of acute hepatocellular failure is acute virus hepatitis but an identical picture can be related to drugs particularly hydrazine amine oxidase inhibitors such as phenelzine (Nardil) or to exposure, usually multiple, to the anaesthetic agent halothane (fluothane) (Peters, et al., 1969; Klion, Schaffner \& Popper, 1969). Suicidal attempts using paracetamol are increasing as a cause of acute hepatocellular failure. It may also follow surgical shock with or without Gram-negative septicaemia and fatty liver of the last trimester of pregnancy. (Table 1).

Prognosis is poor, the condition being fatal in $90 \%$ of cases if deep coma ensues.

Danger signals in viral hepatitis

One of the earliest signs is change in the per-
TABLE 1. Royal Free Hospital fulminant hepatitis 1959-70

\begin{tabular}{lcc}
\hline Number & 83 \\
Viral hepatitis & 63 \\
Drugs & 19 \\
$\quad$ Halothane & \\
$\quad$ Amine oxidase inhibitor & 9 & \\
$\quad$ Anti-TB & 3 & \\
$\quad$ Paracetamol & 1 & \\
Fatty liver pregnancy & 1 \\
Survived & $9(12 \%)$ \\
Died & 74 \\
\hline
\end{tabular}

sonality. The patient may show episodes of antisocial behaviour or character disturbance. Nightmares, headache and dizziness are other inaugural non-specific symptoms. Violent behaviour is common in children, who may also have fits. The acute organic reaction with delirium and clouding of consciousness rapidly progresses to coma. Tremor may be transient and overlooked. Fetor hepaticus is a good sign. Daily estimation of hepatic size is very useful in patients with acute virus hepatitis: a shrinking liver is a danger signal. If possible, an electroencephalogram should be done, when slowing of the mean frequency is another early danger signal.

The serum transaminase, serum bilirubin or blood ammonia levels are not particularly helpful as prognostic signs.

\section{Failure of the Krebs-Henselheit cycle}

Enzymes involved in this cycle are found in the mitochondria (Fig. 1). These enzymes are responsible for the metabolism of ammonia, which is produced in the gut and to a much lesser extent by the kidney and stomach, to urea. In liver cell failure therefore one would expect an accumulation of ammonia in the blood and a reduction in the blood urea concentration. This is indeed so for blood ammonium levels are raised in fulminant hepatitis (Phear, Sherlock \& Summerskil, 1955) and in a series of fulminant hepatitis patients seen at the Royal Free Hospital, seven of twenty-nine had a blood urea level of less than $15 \mathrm{mg} / 100 \mathrm{ml}$. In the later stages, blood urea rises due to failure of renal excretion and to absorption of digested blood from the gut. The connection between blood ammonium and hepatic 


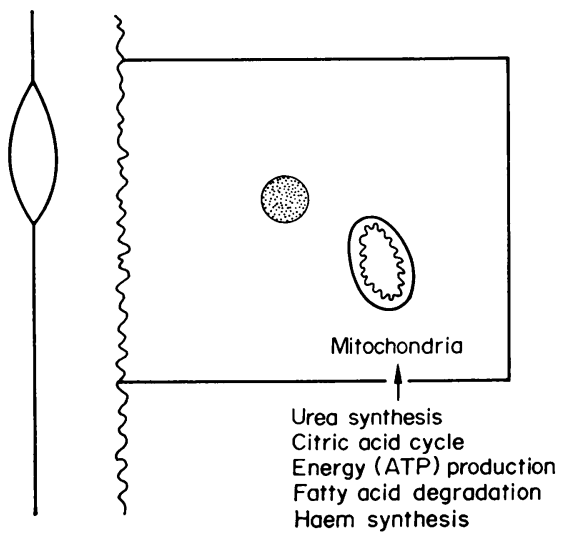

Fig. 1. Diagram of the hepatocyte at a subcellular level. The mitochondria contain the enzymes of the KrebsHenseleit cycle. Failure results in high blood ammonia and low urea levels.

coma has been much discussed (Gabuzda, 1967). In general, the connection is more tenuous in acute hepatocellular failure than in the chronic encephalopathy following portacaval shunting. Nevertheless, efforts must be made to reduce it for the blood ammonia also reflects the level of other nitrogenous and also possibly toxic products of bacterial metabolic action in the intestines. The patient is therefore given no protein by mouth and the colon is emptied by a high enema and by a magnesium sulphate purge. The enema should be of neutral or slightly acid $\mathrm{pH}$ as alkaline solutions favour the absorption of ammonia from the colon. Lactulose, a dissacharid not altered by intestinal lactase should be given in a dose of $40 \mathrm{ml}$ twice daily by mouth. The lactulose is split by colonic bacteria to organic acids so making the contents of the colon more acid and preventing ammonia absorption. Neomycin is given in a dose of $1 \mathrm{~g}$ daily by mouth four times a day.

\section{Hypoglycaemia}

Glycogen granules are stored in the hyaloplasm (Fig. 2). Glycogenolysis is effected by an enzyme on the rough reticulum, glucose-6-phosphatase (Fig. 3). Hypoglycaemia is rare in most forms of human liver disease, but may complicate fulminant virus hepatitis, especially in children. In one large series, two of twenty-nine patients with acute hepatocellular failure had blood glucose levels less than $40 \mathrm{mg} / 100 \mathrm{ml}$ (Jones et al., 1967). Hypoglycaemia may sometimes be very persistent and intractable (Samson, et al., 1967). It is essential that the blood glucose be measured repeatedly in patients with fulminant hepatitis. This should be done at least 4-hourly. At least 1600 calories are supplied daily as glucose drinks or as $20 \%$ glucose through a gastric drip. Twenty per cent or $40 \%$ dextrose is

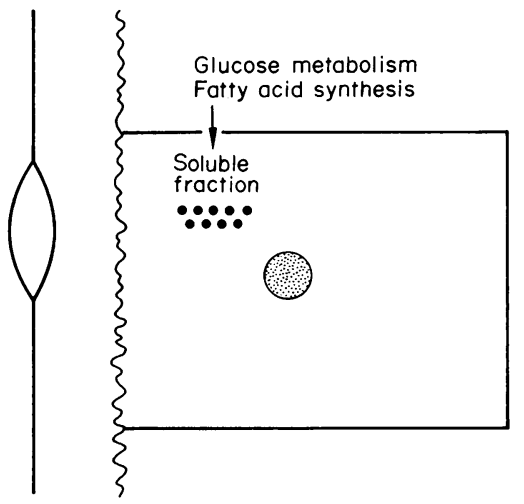

FIG. 2. The soluble fraction contains enzymes concerned with glucose metabolism.

given via anticubital or femoral vein into the innominate vein or vena cava. Alternatively, $20 \%$ laevulose may be used; this is less irritant to the veins. Alertness to the possibility of hypoglycaemia is an important practical consideration in the management of fulminant viral hepatitis.

\section{Albumin synthesis}

This is a function of the ribosomes of the rough endoplasmic reticulum (Fig. 3). Reduced synthesi of albumin has been shown in patients with live disease (Tavill, Craigie \& Rosenoer, 1968). After recovery from hepatocellular failure, intravenous salt-poor albumin is often useful for replenishing the reduced pool of albumin. The dose required is of the order of $25 \mathrm{~g}$ daily until the serum albumin concentration is normal.

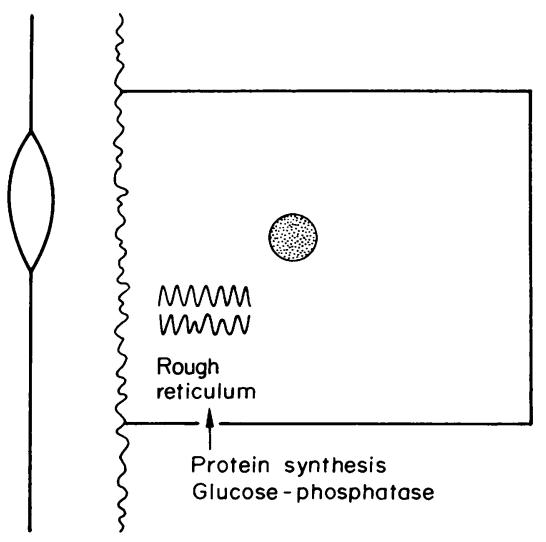

Fig. 3. The rough reticulum is responsible for protein synthesis and contains the enzyme glucose-6-phosphatase. 


\section{Blood coagulation (Table 2)}

Failure of the blood to clot is particularly important in patients with fulminant hepatitis and bleeding is a frequent cause of death. It is shown by bruising in tissues, bleeding from mucous membranes, from the gastro-intestinal tract and into the brain. The patient in acute hepato-cellular failure often dies

TABLE 2. Clotting problems. Monitor platelets, prothrombin time

\begin{tabular}{ll}
\hline \multicolumn{1}{c}{ Treatment } & Corrects \\
\hline Vitamin $\mathrm{K}_{\mathbf{1}}$ & Bile salt deficiency \\
$\quad(10 \mathrm{mg}$ i.m. $)$ & Pro., VII, X \\
Stored blood & Pro., VII, IX, X \\
Fresh whole blood & V, VII, IX, X, platelets \\
Fresh frozen plasma & V, VII, IX, X \\
Platelet infusions & Platelets \\
Calcium gluconate & Citrate intoxication \\
$(10 \mathrm{ml} / \mathrm{l})$ & Fibrinolysis \\
Heparin & Consumptive coagulopathy \\
\hline
\end{tabular}

bleeding from everywhere and in spite of all therapeutic efforts. The causes of this failure of blood clotting are multiple and complex. The liver synthesises most of the factors concerned in blood coagulation. They have a short half-life and rapidly become deficient when liver cell function fails. This is reflected in the one-stage prothrombin time being reduced usually to $30 \%$ or less. The extent of the reduction is an excellent prognostic guide (Cook \& Sherlock, 1965). Factors VII and X, and prothrombin require Vitamin $\mathrm{K}$ for their synthesis. They therefore depend on adequate amounts of bile salts being present in the intestine. Although this is a minor factor in the clotting problems of hepatocellular disease, it is worth giving $10 \mathrm{mg}$ of Vitamin $\mathrm{K}_{1}$ intramuscularly to all patients with nonhaemolytic jaundice whether it be predominantly cholestatic or predominantly hepatocellular.

The liver cell manufactures prothrombin, factors V, VII, IX and $X$ and fibrinogen. Deficiencies of prothrombin, factors VII, IX, and $X$ can be corrected by transfusion of stored bank blood. Fresh blood also supplies factor V. Fresh frozen plasma can also be used but is difficult to prepare, large quantities are required and administration has to be repeated (Spector et al., 1966). Platelet deficiency is of multiple causation. An enlarged spleen may sequester platelets, stored blood is very poor in platelets, any method of hepatic support may withdraw platelets from the circulation. Perfusion through the isolated pig's liver for instance, leads to loss of platelets in the sinusoids of the donor liver. Finally, attempts at intravascular clotting in response to capillary bleeding leads to consumption of platelets and other clotting factors such as fibrin are consumed at the same time (consumption coagulo- pathy). This problem is treated by using fresh blood (which contains platelets) for transfusion and by platelet-rich transfusions. Fibrinolysis is in fact usually of minor importance although a shortened half-life of ${ }^{131}$ I-fibrin has been shown in patients with fulminant hepatitis (Rake et al., 1970). Intravascular clotting and consumption of fibrin is shown by the finding of proteolytic degradation products in the peripheral blood (fibrin-split products) and these should be searched for in the presence of a profound haemorrhagic diathesis. These products interfere with platelet aggregation (Thomas, Ream \& Stuart, 1967) and also interfere with normal fibrinogen polymerization. If they are found the cautious use of heparin $(10,000$ units intravenously given continuously over $4 \mathrm{hr}$ ) must be considered. Its use must be monitored by thrombin consumption tests and by tests for fibrin-split products.

Finally the transfusion of large quantities of stored blood or plasma raises the possibility of citrate intoxication. This would be expected to be more common in those with hepatic disease for the liver metabolises citrates. High concentrations of serum citrate have been observed during multiple transfusions in patients with liver disease and these may depress the serum ionic calcium. Intravenous calcium gluconate supplements should be given $(10 \mathrm{ml}$ slowly for each litre of concentrated blood transfused). In general, however, the risk is small provided the blood is not infused at a rate greater than 1 pint in $10 \mathrm{~min}$.

\section{The place of corticosteroid therapy}

At the present time, whether corticosteroids are given in the treatment of fulminant hepatitis or not, is a matter of individual preference. In one series, large doses of prednisolone (100 $\mathrm{mg}$ a day) were given and nine of twenty-three patients survived (Katz et al., 1962). Others found a much higher mortality despite prednisolone therapy. Burnell and co-workers (1967) found only one survivor in twenty-six and at the Royal Free Hospital, two of forty-four patients with fulminant hepatitis survived after prednisolone while three of twenty-four lived without this medication. Davies and co-workers (1968) quoted six of sixteen survivors from acute fulminant viral hepatitis after cortisone treatment. It could not be predicted which patient would recover and which would succumb. Such diverse results are difficult to interpret. They probably reflect the different type of patient being treated and differences in depth and duration of coma. At least it is clear that viral hepatitis reaching the stage of coma carries an alarmingly high mortality and that corticosteroid therapy cannot be predicted to improve matters greatly.

In one case of fulminant hepatitis, Almeida \& Waterson (1970) found Australia antigen-antibody 
complexes by electron microscopy in the peripheral blood. They postulated that a possible mechanism for the liver cell-membrane injury in fulminant hepatitis might be the presence of injurious antigenantibody complexes. This observation has not been confirmed. If this concept is important, then there might be a place for corticosteroid therapy in the early stages of the disease.

It is also probable that corticosteroids have a beneficial effect on hepatocellular function. They certainly improve the hepatic storage of bromsulphthalein (Cook, Velasco \& Sherlock, 1968) and bilirubin metabolism in the liver cell may be similarly affected. Prednisolone therapy also improves the absolute synthetic rate for albumin in patients with hepatocellular disease (Cain, Mayer \& Jones, 1970).

\section{Circulatory and renal failure}

Many factors contribute to the renal failure of fulminant virus hepatitis. Jaundice, hypokalaemia, infection and haemorrhage predispose to acute tubular necrosis. More often, organic damage to the nephron is not seen histologically, but the disturbance can probably be related to alterations in renal circulation (Schroeder et al., 1967; Brunt et al., 1970). Renal failure does not usually achieve clinical significance, the blood urea level being about 150 $250 \mathrm{mg} / 100 \mathrm{ml}$. Rarely the serum potassium value reaches dangerously high levels and must be reduced, if not by sorbitol, insulin and glucose or ion exchange resins, then by peritoneal or haemodialysis. Persistent hyponatraemia is ominous. It reflects impending cell death. It should not be treated with hypertonic sodium chloride unless there is clear evidence that a profound loss of sodium has occurred from the body.

The patient with fulminant hepatitis should be nursed in an intensive care unit with a special attendant. Fluid overload must be guarded against.

\section{Control of infection}

Respiratory complications may ensue and a parenteral antibiotic such as a large dose of benzylpenicillin or ampicillin may be needed. Tetracyclines are hepatotoxic and should not be given. Gramnegative septicaemias which may be related to long intravenous catheterization must always be anticipated and blood cultures taken. They may be treated with hydrocortisone and cephaloridine.

\section{Temporary hepatic support}

The various ways by which the failing functions of the liver cell can be bolstered have been outlined. There are other methods by which the liver cell can be supported as a whole, even though they may be of only temporary benefit. This form of therapy can only be applied to potentially reversible forms of hepatocellular disease. The therapeutic procedures involved are time-consuming and none has become $\frac{\mathbb{D}}{\mathbb{Q}}$ established. They require specialized and highly trained staff.

\section{Exchange blood transfusion}

Whole blood (preferably fresh) is exchanged. 흠 Clinical improvement could result from the removal $\frac{\bar{\sigma}}{5}$ of toxic substances from the blood or the addition $\Phi$ of deficient factors into the circulation. Trey, Burns \& Saunders, (1966) in Cape Town reported recovery of consciousness after exchange transfusions in seven. patients in hepatic coma due to acute hepatitis; two $\overrightarrow{\vec{\omega}}$ died later. Five of the patients were children and $\stackrel{\omega}{\sigma}$ none had oliguria. Berger and co-workers (1966) reported a dramatic recovery after exchange trans- 3 fusion of one adult, a physician, in hepatic coma due to acute hepatitis. The Fulminant Hepatic Failure $v$ iे Surveillance Study from Boston, Massachusetts $\overrightarrow{0}$ reported results of treatment of 284 patients in stage 4 hepatic coma from ninety-eight centres. One $\stackrel{\oplus}{\mathscr{O}}$ hundred and one did not have any exchange trans- $ᄋ$ fusion and the survival was $9.9 \%$. One hundred and sixty-six had an exchange transfusion and the $c$ survival was $24 \cdot 1 \%$. (Trey et al., 1968). Despite these $<$ results, other reports have been rather disappointing. $\overrightarrow{0}$ Benhamou, Rueff \& Sicot (1968) in a survey of $2{ }^{2}$ published and thirty-six personal cases found recovery of $34.4 \%$ in those treated by exchange transfusions and $39.2 \%$ in those who were not. Results at the Royal Free Hospital have also been disappointing. Nineteen patients with acute hepato- $\frac{O}{\mathbb{D}}$ cellular failure have been treated, seven showed $a \stackrel{ }{\varrho}$ marked lightening in the level of unconsciousness $\overrightarrow{\overrightarrow{0}}$ and eight unequivocal improvement in the EEG 3 pattern, but only two survived. One survivor seems to have made a complete recovery, the other has been persistently jaundiced for 1 year. The remaining $\overline{0}$ 일 patients died at times varying from 3 to 21 days from the onset of coma. At autopsy, liver histology in $\frac{5}{3}$ these patients showed distortion of hepatic architecture of such severity that if survival had occurred, $\frac{\delta}{3}$ the development of a macronodular cirrhosis would

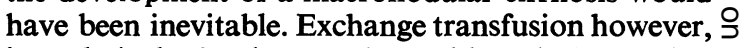
is a relatively simple procedure, although demanding $\rightarrow$ and in a condition with such a high mortality and especially in the young patient, is still worth a trial. N The central venous pressure must be monitored and blood exchanged using a Scribner-Quinton arterio- $N$ venous shunt and the inflow and outflow regulated $N$ by means of two pumps. Large quantities of fresh (drawn within $24 \mathrm{hr}$ ) heparinized blood are required. The first exchange is equal to the blood volume $\frac{\bar{\Phi}}{\Phi}$ calculated from the body weight. If clinical improve- $\stackrel{\oplus}{+}$ ment has not become manifest, a second exchange is performed $24 \mathrm{hr}$ later. An exchange of 5.5 1 in an adult man (weight $70 \mathrm{~kg}$ ) results in replacement of 
about $80 \%$ of the blood volume (Berger et al., 1966). If there has been no improvement after two exchanges, recovery is unlikely and the treatment may be abandoned.

\section{Drug metabolism}

Many drugs are changed by enzymes of the microsomal system in the liver cell. The rate of metabolism of many drugs does seem to be reduced in patients with liver disease but this may be compensated to some extent by the process of enzyme induction. This non-specific enhancement of function follows administration of almost any drug. The patient will almost certainly have had his enzymes induced already to a maximal extent by the many drugs he has received and an additional enzyme inducer such as phenobarbital should not be added to the therapeutic regime. Despite enzyme induction however the patient will have an enhanced response to sedatives and these should be avoided if at all possible. If maniacal excitement, as seen in some patients with fulminant hepatitis, demands control, then half the usual dose of barbitone soluble, which is mainly excreted by the kidney, may be used. Promethazine or diazepam may also be useful. Paraldehyde and morphine must be avoided at all costs.

\section{Plasma-exchange}

The patient's blood is removed and this is followed by return of the packed red cells with fresh frozen donor plasma (Sabin \& Merrett, 1968). It has the advantage that fresh blood is not necessary and stored plasma can be used.

\section{Direct exchange transfusion (cross-circulation)}

This circumvents the problem of blood coagulation difficulties with heparinized blood for the blood from the donor is transfused directly into the recipient, the two subjects lying side by side. No anticoagulants are used. The procedure is carried even further by direct cross-circulation. In this procedure, the patient is cross-circulated, artery to vein, with a volunteer, usually a parent. (Burnell et al., 1967). Of two patients so treated, one recovered from coma but died on the thirteenth day from gastro-intestinal haemorrhage and the other recovered completely. Orthostatic hypotension, fever, urticaria, and thrombocytopaenia may be noted in the donors. Gammaglobulin was given to the donors and none developed hepatitis. Crosscirculation may also be performed between man and baboon. (Saunders et al., 1968; Abouna et al., 1970). Baboons are in short supply in most parts of the world and observations of its value need to be extended and controlled.

\section{Heterologous liver perfusion using the pig's liver}

This employs the isolated pig liver in an extracorporeal circuit (Eiseman et al., 1965). Each liver functions for some $8 \mathrm{hr}$, bile is produced and bilirubin and ammonia extracted from the patient's blood. The bile salts excreted by the pig are predominantly those characteristic of man. The immunological structure of the plasma protein synthesised and returned to the patient remains predominantly that of a pig. In spite of these considerations, there have been no reports of untoward anaphylactic or immunological reactions in patients treated by this technique (Norman et al., 1966). Hitherto, this procedure has not had much success but the patients treated have often suffered from chronic rather than acute liver cell failure and ancillary support has not been given. It was therefore thought worthwhile to set up the method of pig liver perfusion at the Royal Free Hospital and to apply it along with standard medical treatment to patients with acute hepatocellular failure. Of the five patients treated (three female, two male) three suffered from fulminant viral hepatitis, one from paracetamol overdose and one from acute fatty liver of the last trimester of pregnancy. They were all in deep coma with an EEG grade of 4-6 and had not responded to standard medical treatment. They had no underlying disease. Corticosteroids and exchange blood transfusion were not given. Two have survived, one following paracetamol overdose, the other after fulminant viral hepatitis, and have made an apparently complete recovery. Three died, one from liver failure, one from a bleeding duodenal ulcer and one from acute pancreatitis. These results must be extended but the initial impression is favourable as there had only been three survivors in the last sixty-eight patients with acute fulminant hepatitis treated at the Royal Free Hospital (Parbhoo et al., 1971).

\section{Acknowledgments}

This work was supported by the Peter Samuel Fund and the Endowment Fund of the Royal Free Hospital.

\section{References}

Abouna, G.M., Kirkley, J.R., Hull, C.J., Ashcroft, T. \& KERR, D.N.S. (1969) Treatment of hepatic coma by extra corporeal pig-liver perfusion. Lancet, i, 64 .

Abouna, G.M., Serrou, B., Boehmig, H.G., Amemiya, H. \& MartineaU, G. (1970) Longterm hepatic support by intermittent multispecies liver perfusions. Lancet, ii, 291.

AlmeidA, J.D.A. \& WATERSON, A.P. (1969) Immune complexes in hepatitis. Lancet, ii, 983.

Benhamou, J.-P., RuefF, B. \& Sicot, C. (1968) Etude critique des traitements actuels de l'insuffisance hépatique grave. Revue française d'études cliniques et biologiques, $12,651$.

Berger, R.L., Liversage, Chalmers, T.C., Graham, J.H., MCGoldrick, D.M. \& StohlmaN, F. (1966) Exchange transfusions in treatment of fulminant hepatitis. New England Journal of Medicine, 274, 497. 
Brunt, P.W., Varma, R., Hourigan, K. \& Sherlock, S. (1970) Renal blood flow in cirrhosis. (In preparation.)

Burnell, J.M. \& co-workers (1967) Acute hepatic coma, treated by cross-circulation or exchange transfusion. New England Journal of Medicıne, 276, 935.

CaIn, G.D., Mayer, G. \& Jones, E.A. (1970) Augmentation of albumin but not fibrinogen synthesis by corticosteroids in patients with hepatocellular disease. Journal of Clinical Investigations, 49, 2198.

CoOK, G.C. \& Sherlock, S. (1965) Jaundice and its relation to therapeutic agents. Lancet, i, 175.

Cook, G.C., Velasco, M. \& Sherlock, S. (1968) Effect of corticosteroid therapy on bromsulphthalein excretion in active chronic hepatitis. Gut, 9, 270.

Davis, M.A., Peters, R.L., Redeker, A.G. \& Reynolds, T.B. (1968) Appraisal of the mortality in acute fulminant viral hepatitis. New England Journal of Medicine, 278, 1248.

EISEMAN, B., LiEm, D.S. \& RAFFUCCI, F. (1965) Heterologous liver perfusion in treatment of hepatic failure. Annals of Surgery, 162, 329.

GABUZDA, G.J. (1967) Ammonium metabolism and hepatic coma. Gastroenterology, 53, 806.

Jones, E.A., Clain, D., Clink, H.M., MacGillivray, M. \& SHerlock, S. (1967) Hepatic coma due to acute hepatic necrosis treated by exchange blood transfusion. Lancet, ii, 169.

Katz, R., Velasco, M., Klinger, J. \& Alessandri, H. (1962) Corticosteroids in treatment of acute hepatitis in coma. Gastroenterology, 42, 258.

Klion, F.M., SchaffNer, F. \& Popper, H. (1969) Hepatitis after exposure to halothane. Annals of Internal Medicine, 71, 467.

LePore, M.J. \& MARTel, A.J. (1970) Plasmapheresis with plasma exchange in hepatic coma. Annals of Internal Medicine, 72, 165.

Norman, J.C., SARAvis, C.A., Brown, M.E. \& MCDermott, W.V. (1966) Immunochemical observations in clinical heterologous (xenogeneic) liver perfusions. Surgery, 60, 179.

Parbhoo, S.P., Kennedy, J., James, I.M., Chalstrey, L.J., Ajduk iewicz, A., Brock, P.J., Xanalatos, C., SAyer, P. \& SHERLOCK, S. (1971) Extracorporeal pig-liver perfusion in treatment of hepatic coma due to fulminant hepatitis. Lancet, i, 659.
Peters, R.L., Edmondson, H.A., Reynolds, T.B., Meister J.C. \& CURPHEY, T.J. (1969) Hepatic necrosis associated with halothane anaesthesia. American Journal of Medicine, 47, 748.

Phear, E.A., Sherlock, S. \& Summerskill, W.H.J. (1955) Blood ammonium levels in liver disease and 'hepatic coma'. Lancet, i, 836.

Rake, M.O., Flute, P.T., Pannell, G. \& Williams, R. (1970). Intravascular coagulation in acute hepatic necrosis. Lancet, i, 533.

Ritt, D.J., Whelan, G., Werner, D.J., Eigenbrodt, E.H., SCHENKer, S. \& Combes, B. (1969) Acute hepatic necrosis with stupor or coma. An analysis of thirty-one patients. Medicine (Baltimore), 48, 151.

Sabin, S. \& Merritt, J.A. (1968) Treatment of hepatic coma in cirrhosis by plasmaphoresis and plasma infusion (plasma exchange). Annals of Internal Medicine, 68, 1.

Samson, R.I., Trey, C., Timme, A.H. \& SAunders, S.J. (1967) Fulminating hepatitis with recurrent hypoglycaemia and haemorrhage. Gastroenterology, 53, 291.

SAUNDERS, S.J. et al. (1968) Acute hepatic coma treated by cross-circulation with a baboon and by repeated exchange transfusions. Lancet, ii, 585.

Schroeder, E.T., Shear, L., Sancettas, M. \& Gabuzda, ש G.J. (1967) Renal failure in patients with cirrhosis of the liver. 1. Description of clinical and laboratory features. American Journal of Medicine, 43, 887.

Spector, I., CoRn, M. \& Ticktin, H.E. (1966). Effect of plasma transfusions on the prothrombin time and clotting factors in liver disease. New England Journal of Medicine 275, 1032.

Tavill, A.S., Craigie, A. \& Rosenoer, V.M. (1968) The measurement of the synthetic rate of albumin synthesis i⿱⺈ man. Clinical Science, 34, 1.

Thomas, D.P., Ream, V.J. \& Stuart, R.K. (1967) Platele aggregation in patients with Laennec's cirrhosis of the liver. New England Journal of Medicine, 276, 1344.

Trey, C., Burns, D.G. \& SAunders, S.J. (1966) Treatment of hepatic coma by exchange blood transfusion. New England Journal of Medicine, 274, 473.

TREY, C., (1968) Second progress report, fulminant hepatic failure surveillance study, Boston. Quoted in Leader, New England Journal of Medicine, 278, 1287. 